\title{
Burr-Hole Evacuation of Chronic Subdural Haematoma: A Comparative Study between Evacuation With and Without Drainage
}

\author{
MOHAMED H. ALY, M.D.; AHMED M. SALAH, M.D. and HASHEM M. ABOUL-ELA, M.D. \\ The Department of Neurosurgery, Faculty of Medicine, Cairo University
}

\begin{abstract}
Background: Chronic Subdural Haematomas (CSDH) are relatively common in the geriatric age group. There are several alternatives for surgical management: Burr-hole evacuation, twist drill craniostomy and craniotomy. The widely performed procedure is burr hole evacuation with drainage.
\end{abstract}

Aim of Study: Evaluation of the surgical treatment of chronic subdural haematomas, we studied two surgical options of CSDH: Burr-hole evacuation with and without drainage.

Material and Methods: In this retrospective study, we analyzed patients with chronic subdural haematomas subjected to surgery in our institute. A total of 72 patients were studied: 38 underwent burr-hole evacuation and irrigation with postoperative drainage (Group D) and 30 were operated without drainage (Group ND).

Results: There was no case of recurrence in the 6-month post-operative period. The average period of hospitalization, the number of post-operative complications, the incidence of rebleeding and the amount of the expansion of the cerebral cortex did not differ between the two groups.

Conclusion: The vital step of CSDH surgery is meticulous irrigation during the operation. To insert a drain or not, is not of great value.

Key Words: Chronic Subdural Haematomas (CSDH).

\section{Introduction}

CHRONIC Subdural Haematomas (CSDH) are relatively common in the geriatric age group. In the general population, yearly incidence is around 5 per 100,000 [1]. Management includes conservative and surgical treatment. There are several options for surgical management: Burr-hole drainage, twist drill craniostomy and craniotomy [2]. The ideal surgical procedure remains debatable. The generally performed procedure is burr hole evacuation with drainage [3]. In this study we studied the practice of burr hole evacuation without drainage in comparison to drainage.

Correspondence to: Dr. Mohamed H. Aly, The Department of Neurosurgery, Faculty of Medicine, Cairo University

\section{Patients and Methods}

In this retrospective study, we enrolled patients with chronic subdural haematomas treated with burr-hole evacuation that were admitted to the Emergency Department of Kasr Al-Ainy University Hospital, Egypt, from January 2018 to December 2018. We excluded patients who underwent craniotomy or conservative management.

Diagnosis was established by history, clinical examination and CT scans. The density of the hematoma was measured from the pre-operative CT image. All patients were either treated with burr-hole evacuation and irrigation with or without drainage. Thus, they were grouped into 2 groups drainage group (D) and no drainage group (ND). The surgical method was made according to the surgeon's preference.

The procedure was performed under general anesthesia. One or 2 holes were drilled at the site of the hematoma determined from pre-operative $\mathrm{CT}$. The dura underwent electric coagulation haemostasis. The dura mater was incised through a snip to allow gradual slow evacuation of hematoma. A soft silicone tube was introduced into the cavity, followed by extensive irrigation with saline until the solution became clear. In Group D, the tube was left as a drain and exited from the scalp approximately $1 \mathrm{~cm}$ from scalp incision. Irrigation is continued till all air was removed. Watertight closure of the wound was ensured. The drain was removed after 2 or 3 days depending on the amount and colour of the drainage fluid. The patients with bilateral CSDH underwent simultaneous bilateral burr-hole evacuation on both sides. In group ND the same steps were made except for the placement of the drain. Patients of both groups were told to lay flat in bed for 24-48 hours post-operatively. 
A post-operative CT scan was performed on all patients to evaluate whether the hematoma had recurred. Length of hospital stay was noted, and follow-up for 6 months was performed for all patients.

\section{Results}

A total of 72 patients were enrolled in the study. These patients had no recent history of intake of anticoagulation and antiplatelet drugs. The age of patients ranged from 23 to 87 years. $(n=38$; group D) ( $n=34$; group ND). Of the D group, 31 were male, and 7 were female (age, 40-80 years; average, 74.6 years). Of the BI group, 19 were male, and 15 were female (age, 36-82 years; average, 77.1 years). The ages of the two groups did not differ significantly. Of all the cases, 67 had a history of trauma while 5 denied any history of trauma (Table 1).

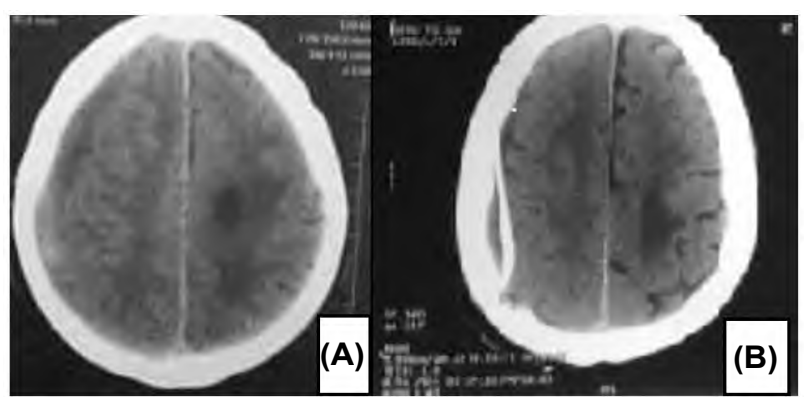

Fig. (1): A case from group D. A 70-year-old patient with history of head trauma underwent burr-hole evacuation and subdural drainage. (A): Pre-operative CT image, (B): Post-operative CT image showing adequate brain expansion.

CT scans showed lesions of low density in 44 cases, 21 of high density in 10, and of mixed density in 7 (Table 1). From the CT scan, there was a gap between the cortex and skull, ranging approximately 1 to $2 \mathrm{~cm}$ caused by the hematoma. After the surgery, the cortex often could not expand completely, but the gap decreased. We defined the finding of decreasing the gap as "expansion of the cortex". The haemorrhage that happened within the 24-hour post-operative period was defined as a rebleeding case. Two cases of rebleeding occurred in group $\mathrm{D}$, were treated with craniotomy, and recovered well. One case of rebleeding occurred in group ND, which was treated with craniotomy and recovered well. However, the cerebral cortex expanded in almost all cases of both groups (Table 2).

A few patients showed little pneumocephalus, which resolved spontaneously. However, there were no cases of tension pneumocephalus. There was no case of recurrence in the 6-month postoperative period. No seizure or intracranial infection was found. The average period of hospitalization, the number of post-operative complications, the incidence of rebleeding and the amount of the expansion of the cerebral cortex did not differ between the two groups (Table 2).

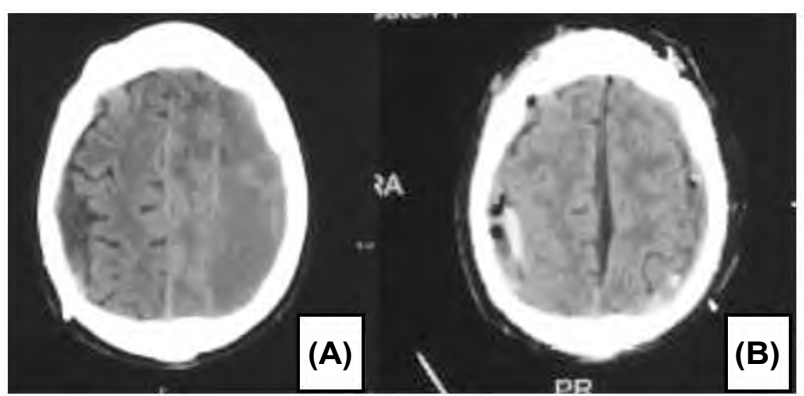

Fig. (2): A case from group ND. A 30-year-old patient with history of head trauma underwent bilateral burr-hole evacuation without drainage. (A): Pre-operative CT image, (B): Post-operative CT image showing adequate brain expansion.

Table (1): Baseline characteristics.

\begin{tabular}{|c|c|c|c|}
\hline Variable & All (n=72) & $\mathrm{D}(\mathrm{n}=38)$ & $\mathrm{ND}(\mathrm{n}=34)$ \\
\hline Mean age (years): & 75.4 & 74.6 & 77.1 \\
\hline$\leq 40$ & $5(7 \%)$ & $3(7.9 \%)$ & $2(5.9 \%)$ \\
\hline $41 \sim 50$ & $9(12.5 \%)$ & $5 \quad(13.2 \%)$ & $4(11.8 \%)$ \\
\hline $51 \sim 60$ & $9(12.5 \%)$ & $4(10.5 \%)$ & $5(14.7 \%)$ \\
\hline $61 \sim 70$ & $18(25 \%)$ & $10(26.3 \%)$ & $8 \quad(23.5 \%)$ \\
\hline $71 \sim 80$ & $25(34.7 \%)$ & $12(31.6 \%)$ & $13(38.2 \%)$ \\
\hline$\geq 81$ & $6(8.3 \%)$ & $4 \quad(10.5 \%)$ & $2(5.9 \%)$ \\
\hline \multicolumn{4}{|l|}{ Sex: } \\
\hline Male & $50(69.4 \%)$ & $31(81.6 \%)$ & $19(55.9 \%)$ \\
\hline Female & $22(30.6 \%)$ & $7(18.4 \%)$ & $15(44.1 \%)$ \\
\hline \multicolumn{4}{|l|}{ Etiological factor: } \\
\hline Trauma & $67(93.1 \%)$ & $37(97.4 \%)$ & $30(88.2 \%)$ \\
\hline \multicolumn{4}{|l|}{ Symptoms: } \\
\hline Headache & $65(90.3 \%)$ & $33(86.8 \%)$ & $32(94.1 \%)$ \\
\hline Limb weakness & $41(56.9 \%)$ & $25(65.8 \%)$ & $16(47.1 \%)$ \\
\hline Coma & $3(4.1 \%)$ & $2(5.3 \%)$ & $1 \quad(3 \%)$ \\
\hline \multicolumn{4}{|c|}{ Hematoma density on CT: } \\
\hline Hypodense & $44(61.1 \%)$ & $23(60.5 \%)$ & $21(61.8 \%)$ \\
\hline Mixed & $21(29.2 \%)$ & $13(34.2 \%)$ & $8 \quad(23.5 \%)$ \\
\hline Hyperdense & $7 \quad(9.7 \%)$ & $2(5.3 \%)$ & $5 \quad(14.7 \%)$ \\
\hline
\end{tabular}

Table (2): Days of hospitalization, rebleeding, expansion of cerebral cortex in the two groups.

\begin{tabular}{llll}
\hline Variable & All $(\mathrm{n}=72)$ & $\mathrm{D}(\mathrm{n}=38)$ & $\mathrm{ND}(\mathrm{n}=34)$ \\
\hline $\begin{array}{l}\text { Hospitalization: } \\
\quad 44\end{array}$ & $11(15.3 \%)$ & $6(15.8 \%)$ & $5(14.7 \%)$ \\
$\quad 4 \sim 7$ & $23(31.9 \%)$ & $11(28.9 \%)$ & $12(35.3 \%)$ \\
$7 \sim 10$ & $29(40.3 \%)$ & $16(42.1 \%)$ & $13(38.2 \%)$ \\
$>10$ & $9(12.5 \%)$ & $5(13.2 \%)$ & $4(11.8 \%)$ \\
Rebleeding: & & & \\
$\quad$ Rebleeding & $3(4.2 \%)$ & $2(5.3 \%)$ & 1 \\
$\quad$ No rebleeding & $69(95.8 \%)$ & $36(94.7 \%)$ & $35(97.1 \%)$ \\
Expansion of cerebral & & & \\
cortex: & & & \\
$\quad$ No expansion & $2(2.8 \%)$ & $1(2.6 \%)$ & 1 \\
$\quad$ Expanded & $70(97.2 \%)$ & $37(97.4 \%)$ & $33(97.1 \%)$ \\
\hline
\end{tabular}




\section{Discussion}

Conventional surgical methods used to treat CSDH include twist-drill craniostomy with or without drainage, burr-hole craniostomy with or without drainage, and craniotomy [1,4-6]. The ideal surgical method remains a controversy. Most surgeons prefer craniostomy with drainage. However, in several studies drainage is associated with a higher the recurrence rate than evacuation without drainage [7-10]. Javadi et al., studied single burrhole operations with or without drainage. They found no difference in recurrence rate, postoperative complications, or mortality [11]. Our results are similar to such findings. Medical condition, age, and pre-operative level of consciousness may be related to the rate of post-operative complications.

Some investigators found no relationship between irrigation and the recurrence rate [10], while others did. For example, Erol et al., found that irrigation was superior to drainage [4]. Some authors claim that CSDH may spontaneously resolve. The fate of the hematoma depends on the balance between the rate of absorption, cerebral cortex expansion and the maturation of the neomembrane [12]. We believe that when the neomembrane is mature irrigation is necessary in order to wash the fibrinolytic elements which are abundant in the mature stage. This is more important than simply draining the hematoma. Moreover, it was suggested that the Vascular Endothelial derived Growth Factor (VEGF) and Basic Fibroblast Growth Factor (bFGF) levels may be involved in the pathophysiology of the condition [3]. After irrigation, the balance becomes restored and may lead to cure. Our results show no difference between drainage or no drainage regarding cortex expansion. This shows the importance of irrigation as it the only available tool to break the balance.

Several authors compared the two techniques by the recurrence rates [13-16]. We found no difference between the two groups of the study with respect to hospitalization time and recurrence rate. The insertion of a drain is not without risks including inadvertent suturing of the drain requiring reoperation for removal, pneumocephalus, cerebrospinal fluid leak, and intracranial bleeding [17]. Thus, we prefer evacuation with copious irrigation without post-operative drainage.

\section{Conclusion:}

We believe that meticulous irrigation during the procedure is the key to a favourable outcome. Our results reveal that placement of a drain does not affect outcome. We offer this method as a safe alternative with acceptable results. A study of a larger scale with randomization might shed more light on this operative technique.

\section{References}

1- SANTARIUS T., KIRKPATRICK P.J., GANESAN D., CHIA H.L., JALLOH I., SMIELEWSKI P., et al.: Use of drains versus no drains after burr-hole evacuation of chronic subdural haematoma: A randomised controlled trial. Lancet [Internet], Sep., 374 (9695): 1067-73. Available from: https://linkinghub.elsevier.com/retrieve/pii/ S0140673609611156, 2009.

2- DUCRUET A.F., GROBELNY B.T., ZACHARIA B.E., HICKMAN Z.L., DeROSA P.L., ANDERSON K., et al.: The surgical management of chronic subdural hematoma. Neurosurg. Rev. [Internet]. Apr. 10, 35 (2): 155-69. Available from: http://link.springer.com/10.1007/s10143011-0349-y, 2012.

3- YADAV Y., PARIHAR V., NAMDEV H. and BAJAJ J.: Chronic subdural hematoma. Asian J. Neurosurg. [Internet], 11 (4): 330. Available from: http://www.asianjns.org/ text.asp?2016/11/4/330/145102, 2016 .

4- EROL F.S., TOPSAKAL C., FAIK OZVEREN M., KAPLAN M. and TIFTIKCI M.T.: Irrigation vs. closed drainage in the treatment of chronic subdural hematoma. J. Clin. Neurosci. [Internet]. Apr., 12 (3): 261-3. Available from: https://linkinghub.elsevier.com/retrieve/pii/ S0967586804000645, 2005.

5- PAHATOURIDIS D., ALEXIOU G.A., FOTAKOPOULOS G., MIHOS E., ZIGOURIS A., DROSOS D., et al.: Chronic subdural haematomas: A comparative study of an enlarged single burr hole versus double burr hole drainage. Neurosurg. Rev. [Internet]. Jan. 7, 36 (1): 1515. Available from: http://link.springer.com/10.1007/ s10143-012-0412-3, 2013.

6- KANSAL R., NADKARNI T. and GOEL A.: Single versus double burr hole drainage of chronic subdural hematomas. A study of 267 cases. J. Clin. Neurosci. [Internet], Apr., 17 (4): 428-9. Available from: https://linkinghub.elsevier. com/retrieve/pii/S0967586809006201, 2010.

7- KIYMAZ N., YILMAZ N. and MUMCU C.: Controversies in chronic subdural hematoma: Continuous drainage versus one-time drainage. Med. Sci. Monit. [Internet], May, 13 (5): CR240-3. Available from: http://www.ncbi. nlm.nih.gov/pubmed/17476197, 2007.

8- KOMOTAR R.J., STARKE R.M. and CONNOLLY E.S.: The Role of Drain Placement Following Chronic Subdural Hematoma Evacuation. Neurosurgery [Internet], Feb. 1, 66 (2): N15-6. Available from: https://academic.oup. com/neurosurgery/article/66/2/N15/2555965, 2010.

9- SANTARIUS T., QURESHI H.U., SIVAKUMARAN R., KIRKPATRICK P.J., KIROLLOS R.W. and HUTCHINSON P.J.: The Role of External Drains and Peritoneal Conduits in the Treatment of Recurrent Chronic Subdural Hematoma. World Neurosurg [Internet], Jun., 73 (6): 747 50. Available from: https://linkinghub.elsevier.com/ retrieve/pii/S1878875010001555, 2010.

10- WEIGEL R.: Outcome of contemporary surgery for chronic subdural haematoma: Evidence based review. J. Neurol. Neurosurg. Psychiatry [Internet], Jul. 1, 74 (7): 937-43. 
Available from: http://jnnp.bmi.com/cgi/doi/10.1136/ jnnp.74.7.937, 2003.

11- JAVADI A., AMIRJAMSHIDI A., ARAN S. and HOSSEINI S.H.: A Randomized Controlled Trial Comparing the Outcome of Burr-Hole Irrigation with and without Drainage in the Treatment of Chronic Subdural Hematoma: A Preliminary Report. World Neurosurg. [Internet], May, 75 (5-6): 731-6. Available from: https://linkinghub. elsevier.com/retrieve/pii/S1878875010009976. 2011.

12- LEE K.S.: ReviewNatural history of chronic subdural haematoma. Brain Inj. [Internet], Apr. 3, 18 (4): 351-8. Available from: http://www.tandfonline.com/doi/full/ 10.1080/02699050310001645801, 2004.

13- KALIAPERUMAL C., KHALIL A., FENTON E., OKAFO U., KAAR G., O'SULLIVAN M., et al.: A prospective randomised study to compare the utility and outcomes of subdural and subperiosteal drains for the treatment of chronic subdural haematoma. Acta Neurochir (Wien) [Internet]., Nov. 30, 154 (11): 2083-9. Available from: http://link.springer.com/10.1007/s00701-012-1483-1. 2012.

14- OHBA S., KINOSHITA Y., NAKAGAWA T. and MURAKAMI H.: The risk factors for recurrence of chronic subdural hematoma. Neurosurg. Rev. [Internet], Jan. 14;
36 (1): 145-50. Available from: http://link.springer.com/ 10.1007/s10143-012-0396-z, 2013.

15- SOUSA E.B., BRANDÃO L.F., TAVARES C.B., BORGES I.B., NETO N.G.F. and KESSLER I.M.: Epidemiological characteristics of 778 patients who underwent surgical drainage of chronic subdural hematomas in Brasília, Brazil. BMC Surg. [Internet], Dec. 1, 13 (1): 5. Available from: http://bmcsurg.biomedcentral.com/articles/10.1186/ 1471-2482-13-5, 2013.

16- STANISI C' M., HALD J., RASMUSSEN I.A., PRIPP A.H., IVANOVIC' J., KOLSTAD F., et al.: Volume and densities of chronic subdural haematoma obtained from $\mathrm{CT}$ imaging as predictors of post-operative recurrence: A prospective study of 107 operated patients. Acta Neurochir (Wien) [Internet]. Feb. 11, 155 (2): 323-33. Available from: $\mathrm{http}: / /$ link.springer.com/10.1007/s00701-012-15650. 2013.

17- WANG W., LIU H. and YANG J.: Burr hole craniostomy irrigation with and without drainage during surgical treatment of chronic subdural hematoma: A retrospective study of 87 cases. Turk. Neurosurg. [Internet], Available from: http://www.turkishneurosurgery.org.tr/ summary_en_doi.php3?doi=10.5137/1019-5149.JTN.19747-16.2, 2017.

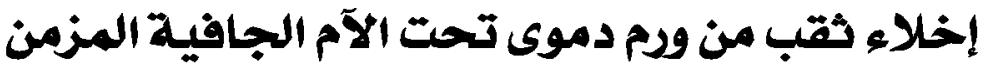 دراسة مقارنة بين الإخلاء بالصرف أو بلدونه}

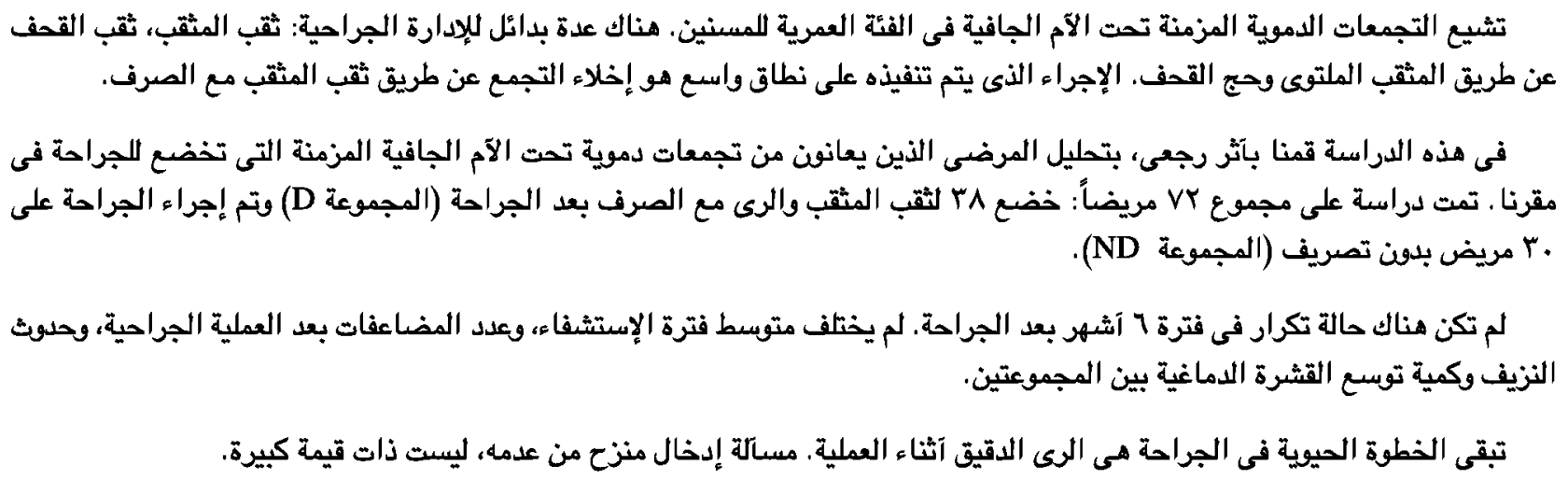

